\title{
Promoting physical activity in Brazil: the promise and the challenge
}

\author{
Diana C. Parra ${ }^{1}$ \\ Ross C. Brownson ${ }^{12}$ \\ 1. Prevention Research Center in St. Louis, \\ Brown School, Washington University in \\ St. Louis, St. Louis, Missouri, USA \\ 2. Division of Public Health Sciences and \\ Alvin J. Siteman Cancer Center, School of \\ Medicine, Washington University in St. \\ Louis, St. Louis, Missouri, USA
}

Brazil is one of the few countries around the world that has recognized the important priority of physical activity promotion and has granted it a prominent place on the national agenda. The Brazilian government, along with other important non-governmental organizations and academic institutions, are working together to support research, practice, and policy for promoting physical activity. The Ministry of Health of Brazil has supported the creation of a national network of researchers and practitioners organized around the promotion and development of infrastructure that supports the adoption of healthy lifestyles, including the practice of community based physical activity'. One of the most recent groundbreaking initiatives is the creation of the Academia da Saude, a national program that expands a physical activity intervention to 4,000 new municipalities around the country over the next 5 years ${ }^{2}$ Academia da Saude is based on the successful experience of the program Academia da Cidade which began in the city of Recife ${ }^{3}$ and has been effectively implemented and evaluated in other cities from Brazil ${ }^{4-6}$. The program offers physical activity classes (e.g., aerobics, yoga, tai chi, dance, stretching) as well as assessment, nutrition counseling and chronic disease prevention. The Academia programs are delivered by trained professionals, and importantly, they are free of charge to participants. Academia da Cidade was first evaluated by Project GUIA, a collaboration between national and international government and academic institutions from the United States (U.S.) and Brazil, including the U.S. Centers for Disease Control and Prevention (CDC), the Prevention Research Center in St. Louis, and the Ministry of Health of Brazil7 Project GUIA has been highly successful and serves as an example for cross national and transdisciplinary collaboration ${ }^{8}$.

Another exemplary initiative around physical activity taking place in Brazil is the Brazilian Society for Physical Activity and Health ${ }^{9}$. The society sponsors the Brazilian Journal for Physical Activity and the Brazilian Congress in Physical Activity and Health, among other important national events. One of the most recent events sponsored by the Society was the VIII Brazilian Congress in Physical Activity and Health held in Gramado Porto Alegre in Brazil in November $2011^{10}$. The Congress had the participation of international and nationally recognized experts in physical activity and was successful in expanding knowledge and networking among more than 1,000 participants. Moreover, a series of books and reports on physical activity in Brazil have recently been published, providing further evidence of the breadth of inspired young professionals, many in the area of physical education, whose training in physical activity epidemiology and other core disciplines has now become a norm within their professional development ${ }^{11-13}$. A network of universities throughout Brazil is supporting training and capacity building in the area of physical activity epidemiology. Many of the things happening in Brazil are due in part to the excitement around physical activity research and practice as a relatively new field when compared to other developed regions of the world. In Brazil and other countries from Latin America, there is still much that needs to be learned about promotion and practice of physical activity, particularly as it relates to identifying effective interventions and then translating these to populations at high risk.

Strong evidence that physical activity works to promote health and prevent chronic disease is documented ${ }^{14}$. Physical activity, and not just structured exercise or organized sports has been shown to decrease the risk for developing an array of chronic diseases including cancer and obesity ${ }^{15}$. While much more needs to be done in terms of informational approaches, providing resources and opportunities to be physically active is crucial, and is an area where Brazil seems to be getting it right. For many years, too much focus was paid to individual-level approaches for promoting physical activity (e.g., informational interventions) without paying adequate attention to environmental and policy approaches (e.g., accessibility to infrastructure and creation of free and public programs). These types of policy-approaches hold even more significance for disenfranchised populations who may otherwise not be able to afford a gym membership or enroll in other organized and structured activities. Under- 
served populations may also face additional environmental barriers and challenges such as traffic and crime safety, as well as poor and insufficient urban infrastructure not conducive to physical activity. Specifically as it relates to women, given their role of home care provider, there are fewer opportunities to engage in physical activity, thus programs such as those being offered by local governments (i.e. Academia da Cidade) offer a convenient way of engaging in physical activity while children are at school. It has been suggested that the physical activity programs implemented by Brazilian governments are important strategies for reducing health disparities among vulnerable populations such as older adults, women and low-income individuals ${ }^{16}$.

Despite these gains and promise, the promotion of physical activity is lacking a comprehensive approach from all sectors, including informational, resource oriented, and also advocacy and empowerment by civil society. We, as researchers and practitioners, have an opportunity to inform the public about their right to be active and their right to demand safe and affordable opportunities for physical activity from their local, regional, and national governments. Physical activity can be a tool of empowerment and a way to promote more individual freedom and control over one's own health. We need to do a much better job in relation to advocacy as we are not only faced with the barrier of convincing the public that physical activity is good for health, but also face the difficult task of persuading high ranking officials to support physical activity policies. Brazil is an example of a country that has made progress in this area, where decision makers are working with the public to promote physical activity.

Countries from the region have much to learn from Brazil. Integrating the model of universal health care with the promotion and access to physical activity seems to be a key component in improving population health. For many years the CDC through the Physical Activity and Health Branch (PAHB) has been supporting international work and research on physical activity. It is highly due to the economic and technical support provided by the $C D C$, that international collaborations such as Project GUIA ${ }^{17}$ and project $\mathrm{GOL}^{18}$ have been successful $^{19}$. In addition, the World Health Collaborating Center for Physical Activity and Health (WHO/CC), an effort that began in 1998 under the leadership of the CDC/PAHB, has been instrumental in supporting promotion of physical activity both nationally and internationally, and it has played a crucial leadership role in placing physical activity high on the agenda of local and national governments around the world, particularly in Latin America ${ }^{20}$. Unfortunately, due to budget pressures, it was decided that after August 2012 the WHO/CC could not be supported in its current home (PAHB). There has been an outpouring of support and gratitude to the Center by many public health leaders, practitioners, and researchers from around the world who can testify to the broad-based impact of the $\mathrm{WHO} / \mathrm{CC}$. The CDC is exploring how it may continue this effort in another home but with a broader non-communicable disease mission.

Sadly, this is not the only way in which efforts to promote physical activity around the world are being hindered. Shortly after the recent United Nations High Level Summit on Non-Communicable Diseases (NCDs) ${ }^{21}$, a political declaration to develop measurable global targets to reduce the burden of NCDs was put in place ${ }^{22}$. This provided a promising opportunity for recognition of physical activity as a priority in the prevention of chronic diseases. However, physical activity was left out of the initial proposed list of target indicators to monitor progress towards reduction of chronic disease ${ }^{23}$. This decision is of great concern, considering that physical activity is a behavior that can and must be measured.

At a time where the U.S. economy is stagnant, it is understandable that Federal agencies like the CDC would want to focus their funding and attention on domestic matters; however, there are clear examples of how lessons learned internationally can also help the U.S. population, especially among the growing Hispanic population ${ }^{24}$. For instance, there are now 70 replications of Ciclovias in the United States, also known as "open streets" initiatives ${ }^{25}$, a program that started in Bogota, Colombia which seeks to promote the use of public spa$\mathrm{ce}$, that would otherwise be occupied by cars, for bicycling, walking, and other recreational activities ${ }^{26}$. Moreover, the program Academia da Cidade, discussed earlier, has also been replicated among Latino populations in San Diego California, as part of a translational grant ${ }^{27}$.

If government funding for public health agencies and other like organizations continue to under-support programs and policies to promote physical activity, the global burden of chronic diseases will continue to rise. In this editorial we have highlighted some of the current promises and challenges for the promotion of physical activity. The Brazilian example is one to be followed, the central role being played by the government, as it relates to the promotion of physical activity, is an unprecedented initiative and one that if fully implemented and carefully evaluated will prove to be fruitful for future population health.

\section{REFERENCES}

1. Knuth, A., et al., Description of the countrywide physical activity network co ordinated by the Brazilian Ministry of Health: 2005-2008. J Phys Act Health, 2010. 7 Suppl 2: p. S253-8.

2. Brasil. Ministério da Saúde. Gabinete do MinistroPortaria $N^{\circ} 719$, in de 07 de abril 2011.

3. Simoes, E.J., et al., Effects of a community-based, professionally supervised intervention on physical activity levels among residents of Recife, Brazil. Am J Public Health, 2009. 99(1): p. 68-75.

4. Gomes, G.A., et al., Walking for leisure among adults from three Brazilian cities and its association with perceived environment attributes and personal factors. Int J Behav Nutr Phys Act, 2011. 8(1): p. 111.

5. Mendonça, B.C., et al., Exposure to a Community-Wide Physical Activity Promotion Program and Leisure-Time Physical Activity in Aracaju, Brazil. Journal of Physical Activity and Health, 2010. 7(2): p. 223-228.

6. Knuth, A.G., et al., Atividade Física no Brasil: uma revisão de evidências em experiências selecionadas, in Saúde Brasil 2010: uma análise da situação de saúde e de evidências selecionadas de impacto de ações de vigilância em saúde, M.d. Saúde, Editor. 2011: Brasilia.

7. Hoehner, C.M., et al., Physical activity interventions in Latin America: a systematic review. Am J Prev Med, 2008. 34(3): p. 224-233.

8. Pratt, M., et al., Project GUIA: A Model for Understanding and Promoting Physical Activity in Brazil and Latin America. Journal of Physical Activity and Health, 2010. 7(Suppl 2): p. S131-S134.

9. Sociedade Brasilera de Atividade Fisica e Saude. 2012 February, 21, 2012 ]; Available from: http://www.sbafs.org.br/index.php.

10. VIII Brazilian Congress in Physical Activity and Health. 2011 February 22, 2012]; Available from: http://www.cbafs.org.br/Home.aspx.

11. Avaliação de Efetividade de Programas de Atividade Física no Brasil. 2011 MINISTÉRIO DA SAÚDE Secretaria de Vigilância em Saúde Departamento de Análise de Situação em Saúde: Brasilia DF.

12. Florindo, A.A. and P.C. Hallal, Epidemiologia da Atividade Física. 2012: Atheneu.

13. Barros, M.V.G., et al., Análise de dados em saúde. 3 ed. 2012: Londrina: Midiograf;.

14. Global Recommendations on Physical Activity for Health. 2010, World Health Organization: Geneva.

15. Physical Activity Guidelines Advisory Committee. Physical Activity Guidelines Advisory Committee Report, 2008. 2008, U.S. Department of Health and Human Services: Washington, DC.

16. Parra, D.C., et al., Assessing physical activity in public parks in Brazil using systematic observation. Am J Public Health, 2010. 100(8): p. 1420-6.

17. Guide for Useful Interventions for Activity in Brazil and Latin America. february 24, 2012]; Available from: http://www.projectguia.org/en/index.html.

18. CDC Special Interest Projects (SIPs) Project Gol - Guide to Obesity Prevention 
in Latin America and U.S. Febrero 24, 2012]; Available from: http://www.sdprc. net/sips-gol.php.

19. Addressing Chronic Diseases in the Americas. 2010 [cited Febrero 24, 2012 Available from: http://www.cdc.gov/prc/stories-prevention-research/stories/ addressing-chronic-disease.htm.

20. CDC/WHO Collaborating Center: Promoting Physical Activity across the Globe. 2009 February 24, 2012]; Available from: http://www.dailystrength.org/ groups/cdc/news/view/1523199.

21. General Assembly of the United Nations President of the 65th Session. 2011 Febrero 24, 2012]; Available from: http://www.un.org/en/ga/president/65/ issues/A-RES-65-238.pdf.

22. Political declaration of the High-level Meeting of the General Assembly on the Prevention and Control of Non-communicable Diseases. 2011.
23. Ralston, J. Developing targets for NCDs: Can we measure Physical Activity? 2012 Febrero 24, 2012]; Available from: http://world-heart-federation.org/ blog/2012/01/26/developing-targets-for-ncds-can-we-measure-physical-activity/.

24. Ennis, S.R., M. Ríos-Vargas, and N. Albert, The Hispanic Population: 2010, in Census brief, U.S.C. Bureau, Editor. 2010.

25. Open Streets Project. 2012 February 22, 2012]; Available from: http://openstreetsproject.org/.

26. Parra, D., et al., Policy and Built Environment Changes in Bogotá and their Im portance in Health Promotion. Indoor Built Environ 2007. 16(4): p. 344-348.

27. Marshall, S. Adaptation of an evidence-based, professionally supervised physical activity intervention for delivery in public settings: AcademiaFit in Prevention Research Centers 2011 Annual Conference. 2011. Atlanta, GA. 